\title{
Study on Correlation Characteristics of PCDD/Fs Isomers Generation during the Coal-Combustion Process with Sludge Mixing
}

\author{
Jinxing Wang ${ }^{1,4^{*}}{ }^{(\mathbb{D}}$, Shuzhou Wei ${ }^{2,3}$, Haiwen Song ${ }^{1}$, Xinlei Wang ${ }^{4}$, Huixin Ren $^{4}$ \\ ${ }^{1}$ School of Energy, Power and Mechanical Engineering, North China Electric Power University, Beijing 102206, China \\ ${ }^{2}$ SanHe Power Plant Ltd., CHN Energy, LangFang 065201, China \\ ${ }^{3}$ Hebei Innovation Center for Coal-fired power station Pollution Control, LangFang 065201, China \\ ${ }^{4}$ School of Energy, Power and Mechanical Engineering, North China Electric Power University, Baoding 071003, Hebei, China \\ Email: wangruoguang860928@126.com
}

Received: 7 December 2021; Revised: 20 January 2022; Accepted: 28 January 2022

\begin{abstract}
The 17 toxic polychlorinated dibenzo-p-dioxins and dibenzofurans (PCDD/Fs) isomers as a persistent and refractory organic pollutant are one of the pollutants produced in solid fuel (including pulverized coal and mixed fuel) combustion, and regulating their distribution characteristics is an important aspect of effectively reducing their toxic equivalent. In this study, a correlation model of PCDD/Fs toxic equivalent was proposed to quantitatively analyze the correlation between $\mathrm{HCl}$ and $\mathrm{SO}_{2}$ concentrations in the reaction atmosphere, meanwhile, a pathway-diagnosis method of $\mathrm{PCDD} / \mathrm{Fs}$ isomers transformation was adopted to analyze the PCDD/Fs distribution characteristics of coal combustion and that mixed with $10 \%$ sludge. The results show that the inflection point for the derivative of the relationship between $\mathrm{HCl}$ concentration and $\mathrm{SO}_{2}$ concentration moves towards the direction of lower $\mathrm{SO}_{2}$ concentration and higher $\mathrm{HCl}$ concentration with the increase of PCDD/Fs toxic equivalent. Besides, the functional pathways of mixing sludge on $\mathrm{PCDD} / \mathrm{Fs}$ generation in coal combustion were obtained by calculating chlorine substitution probability. It has been deduced that five transformation pathways were improved by mixing sludge. Next, the critical pathways of the influence from mixing sludge on the distribution characteristics of PCDD/Fs isomers in coal combustion were analyzed by drawing the percentage content migration diagram of $\mathrm{PCDD} / \mathrm{Fs}$ isomers and the average toxic equivalent migration diagram that combined with the toxic equivalent of PCDD/Fs isomers. The results showed that the main reasons for mixing sludge to further reduce the average toxic equivalent of PCDD/Fs isomers in coal combustion were the increased chlorine substitution probability at the 4-position of 12378 Pentachlorodibenzo-p-dioxin (12378-PeCDD), the decreased chlorine substitution probability at the 4-position of 2378 Tetrachlorodibenzo-p-furan (2378-TeCDF), and the increased total chlorine substitution probability of 23478 Pentachlorodibenzo-p-furan (23478-PeCDF), 123478-Hexachlorodibenzofuran (123478-HxCDF) and 123678-HxCDF respectively. Finally, the functional pathway diagram of $\mathrm{PCDD} / \mathrm{Fs}$ isomers generated from coal combustion with sludge mixing was drawn.
\end{abstract}

Keywords: PCDD/Fs isomers, correlation model, chlorine substitution probability, sludge mixing, function pathway

\section{Introduction}

The combustion process of solid fuels, which includes pulverized coal ${ }^{1}$, municipal solid waste ${ }^{2}$ and plastic waste ${ }^{3}$,

Copyright (C2022 Jinxing Wang, et al.

DOI: https://doi.org/10.37256/fce.3120221275

This is an open-access article distributed under a CC BY license

(Creative Commons Attribution 4.0 International License)

https://creativecommons.org/licenses/by/4.0/ 
has been considered as the main source of PCDDs and PCDFs. PCDD/Fs can participate in the natural circulation and bioaccumulation of humans and animals, and have high toxicity. Therefore, it is closely related to carcinogenicity and teratogenicity, and is classified as persistent organic pollutants. ${ }^{4}$ It's called "dioxins" for short, but in fact it consists of 75 types of PCDD and 135 types of $\mathrm{PCDF}^{5}$, as well as their structures have been shown in Figure 1. It should be pointed out that only 17 toxic PCDD/Fs isomers have attracted much attention, and 2,3,7,8-tetrachlorodibenzo-p-dioxin (TCDD) is the most toxic one. ${ }^{6}$

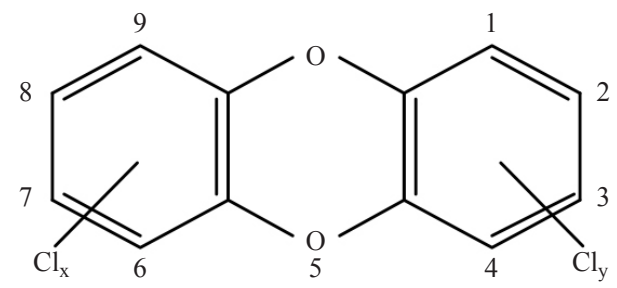

(a)

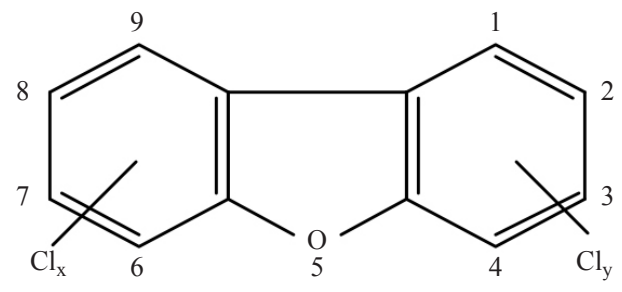

(b)

Figure 1. Molecular structure diagram of $\mathrm{PCDD} / \mathrm{Fs}$

So far, the mechanisms of its formation and inhibition have been widely studied by scholars. At the same time, some important conclusions have been widely recognized by personages of all circles. For example, $\mathrm{PCDD} / \mathrm{Fs}^{7}$ can be directly generated by chlorination of gaseous components such as hydrocarbons and phenols under the action of chlorine sources, and heterogeneous synthesis of combustion products such as $\mathrm{CO}$ and $\mathrm{CO}_{2}$ under the action of catalytic metals on the fly ash surface with carbon residue, $\mathrm{O}_{2}$ and chlorine sources. ${ }^{8}$ Moreover, studies have shown that solid fuels mainly release chlorine in the form of $\mathrm{HCl}$ under high temperature conditions ${ }^{9}$, but in the presence of $\mathrm{O}_{2}$, they can be converted into $\mathrm{Cl}_{2}$ through the Deacon reaction ${ }^{10}$, and the activity of $\mathrm{Cl}_{2}$ is much higher than that of $\mathrm{HCl}^{7}{ }^{7}$ Yifan Wang et al. ${ }^{11}$ studied the inhibitory effect of urea on PCDD/Fs using a sintered tank and analyzed its possible dechlorination inhibitory mechanism. It was found that the toxic equivalent of urea was greatly reduced by mixing urea particles, indicating that urea has the effect of inhibiting chlorination and enhancing dechlorination. Hence, dechlorination becomes an important step to inhibit their formation by mixing inhibitors. Yen-Chen Hsu et al. ${ }^{12}$ have verified that thiourea as an inhibitor can reduce the chlorination degree of PCDD. They hold that the oxidation of organic sulfides or elemental sulfur leads to the formation of $\mathrm{SO}_{\mathrm{X}}$ ( $\mathrm{such}$ as $\mathrm{SO}_{2}$ and $\mathrm{SO}_{3}$ ), which can effectively inhibit the chlorination of Diphenylene dioxide (DD) and Diphenylene oxide (DF) into PCDD/Fs. ${ }^{13}$ Distinctly, the high-S product is an important factor to inhibit PCDD/Fs formation, which provides a theoretical basis for inhibiting their formation by the component deployment of solid fuels. Han $\mathrm{Zi}$-xi et al. ${ }^{14}$ studied the mixed combustion of municipal solid waste and biomass, and the results showed that baking can reduce the total amount of dioxins by $98.63 \%$ and the toxicity equivalent of volatile dioxins by $99.09 \%$. Ri-gang Zhong et al. ${ }^{15}$ carried out the co-combustion experiment of sludge and municipal solid waste, and found that PCDD/Fs production has been reduced by $32 \%$ when $5 \%$ sludge was mixed compared to municipal solid waste combustion alone. In the evaluation of the distribution characteristics of PCDD/Fs, more attention is paid to the ratio of PCDDs to PCDFs, rather than the transformation among PCDD/Fs isomers. For example, Peng Tao Cai et al. ${ }^{16}$ believed that when the ratio of PCDDs to PCDFs is greater than 1, it indicated that de novo synthesis the main way of PCDD/Fs generation. Takashi Fujimori et al. ${ }^{17}$ considered that de novo synthesis should involve the formation of C-C bonds through oxidation and subsequent chlorination, as well as chlorination. For the distinctions of PCDD/Fs isomers, Qiuju Gao et al. ${ }^{18}$ deeply discuss the generation mechanism of PCDDs and PCDFs, respectively. However, the specific generation pathways are still not stated clearly. It has been found from the emission characteristics of PCDD/Fs isomers that there are some significant differences between their actual content distribution characteristics and their toxic equivalent distribution characteristics. For instance, our previous report ${ }^{19}$ pointed out that compared with the conventional incineration mode, the PCDD/Fs production was reduced by $42 \%$ and the toxic equivalent was reduced by $20 \%$ when using Fe-based CLC. Gan Min et al. ${ }^{20}$ by utilizing the suppressing functions of sulfur and calcium 
compounds from $\mathrm{CaSO}_{4}$ decomposing in the fly ash balls, and some similar conclusions have been obtained by detecting PCDD/Fs content and some similar conclusions have been obtained by detecting PCDD/Fs content. Noteworthily, the degree of reduction of PCDD/Fs produced is different from the degree of reduction of toxic equivalent, which indicates that the distribution characteristics and formation pathways of PCDD/Fs isomers have undergone a fundamental change. We calculated the probability of chlorine substitution by the position substitution (PSTS) prediction method ${ }^{21}$, which reflects the intensity of chlorination during the formation of PCDD/Fs, and then we proposed a pathway substitution (PTWS) prediction method ${ }^{22}$ to distinguish PCDD/Fs isomers, but it still does not involve a more specific correlation with $\mathrm{HCl}$ concentration and $\mathrm{SO}_{2}$ concentration.

For this purpose, a correlation model of PCDD/Fs toxic equivalent was first proposed to quantitatively analyze the correlation between $\mathrm{HCl}$ and $\mathrm{SO}_{2}$ concentrations and meanwhile a method ${ }^{22}$ for diagnosing the transformation pathways among PCDD/Fs isomers was adopted to study the functional pathways of mixing sludge on PCDD/Fs isomers for coal combustion by calculating the probability of chlorine substitution as well as analyzing the percentage of PCDD/ Fs isomers and their average toxic equivalent migration. All the selected experimental data are coal combustion and that with $10 \%$ sludge. It is expected to lay a theoretical foundation for low PCDD/Fs emissions from subsequent coal combustion and solid fuel blending by obtaining the correlation characteristics of PCDD/Fs isomers generation from coal combustion with sludge mixing.

\section{Experimental data}

In this work, the experimental data of PCDD/Fs isomers in coal combustion and that mixed with sludge is derived from the existing reports ${ }^{23}$, as shown in Table 1. It can be seen that the toxic equivalent distributions of PCDD/Fs isomers are significantly different under the five operation conditions. Meanwhile, Figure 2 shows the toxic equivalent distribution of 17 toxic PCDD/Fs isomers. Notably, the distribution rule of isomers is not clear, even for the highest toxic equivalent under different conditions. Therefore, it is necessary to carry out a systematic study on the correlation of PCDD/Fs generation and the transformation among PCDD/Fs isomers.

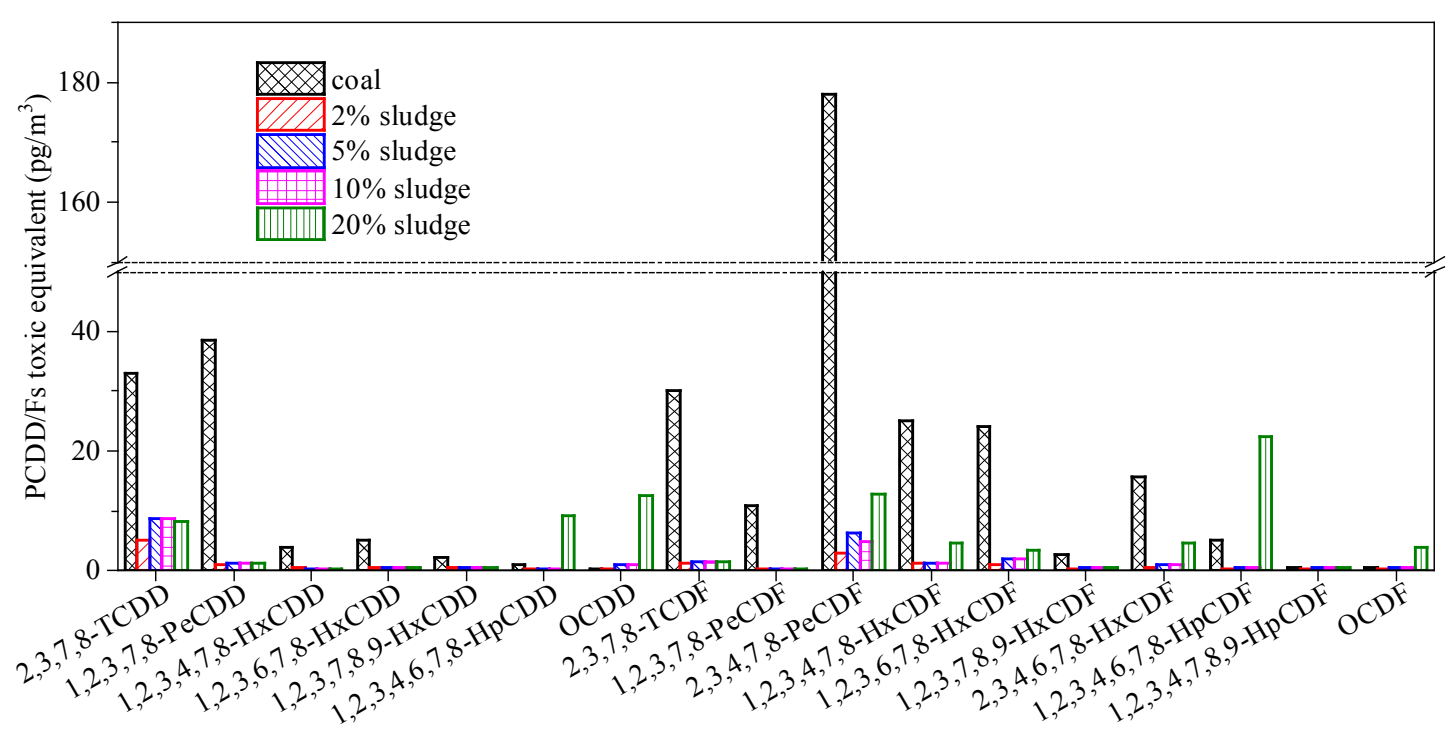

Figure 2. Toxic equivalent distribution of PCDD/Fs isomers 
Table 1. Experimental data on Toxic Equivalent Quantity (TEQ) of PCDD/Fs isomers under two operating conditions

\begin{tabular}{cccc}
\hline Conditions & $\mathrm{HCl}$ concentration $\left(\mathrm{mg} / \mathrm{m}^{3}\right)$ & $\mathrm{SO}_{2}$ concentration $\left(\mathrm{mg} / \mathrm{m}^{3}\right)$ & $\mathrm{PCDD} / \mathrm{Fs}$ toxic equivalent $\left(\mathrm{pg} / \mathrm{m}^{3}\right)$ \\
\hline Coal & 93 & 260 & 152.8 \\
$2 \%$ sludge & 83 & 296 & 17.4 \\
$5 \%$ sludge & 89 & 388 & 27.1 \\
$10 \%$ sludge & 89 & 412 & 25.8 \\
$20 \%$ sludge & 92 & 436 & 87.2 \\
\hline
\end{tabular}

\section{Modeling approach}

\subsection{Theoretical basis}

In the existing literature reports, studies have shown that $\mathrm{HCl}$ concentration is positively correlated with $\mathrm{PCDD} /$ Fs content ${ }^{24}$, in which there is a self-equilibrium relationship between $\mathrm{HCl}$ and $\mathrm{Cl}_{2}$ concentration. ${ }^{7}$ However, the existence of $\mathrm{SO}_{2}$ can react with $\mathrm{Cl}_{2}$ to form $\mathrm{HCl}$, which greatly reduces its chlorination activity. Meanwhile, it has been reported that $\mathrm{SO}_{2}$ can react with catalytic metals to destroy their catalytic properties, which is negatively correlated with the production of $\mathrm{PCDD} / \mathrm{Fs}$. As shown in Figure 3, $\mathrm{HCl}$ concentration was associated with $\mathrm{SO}_{2}$ by setting a linearly correlated function, and a polynomial correlation was determined by combining them into a new function value and matching it with toxic equivalent. On this basis, the process of chlorine migration among PCDD/Fs isomers was further quantitatively analyzed, and the conversion relationship among PCDD/Fs isomers was determined by calculating the chlorine substitution probability. The specific process can be referred to the existing literature. ${ }^{25}$

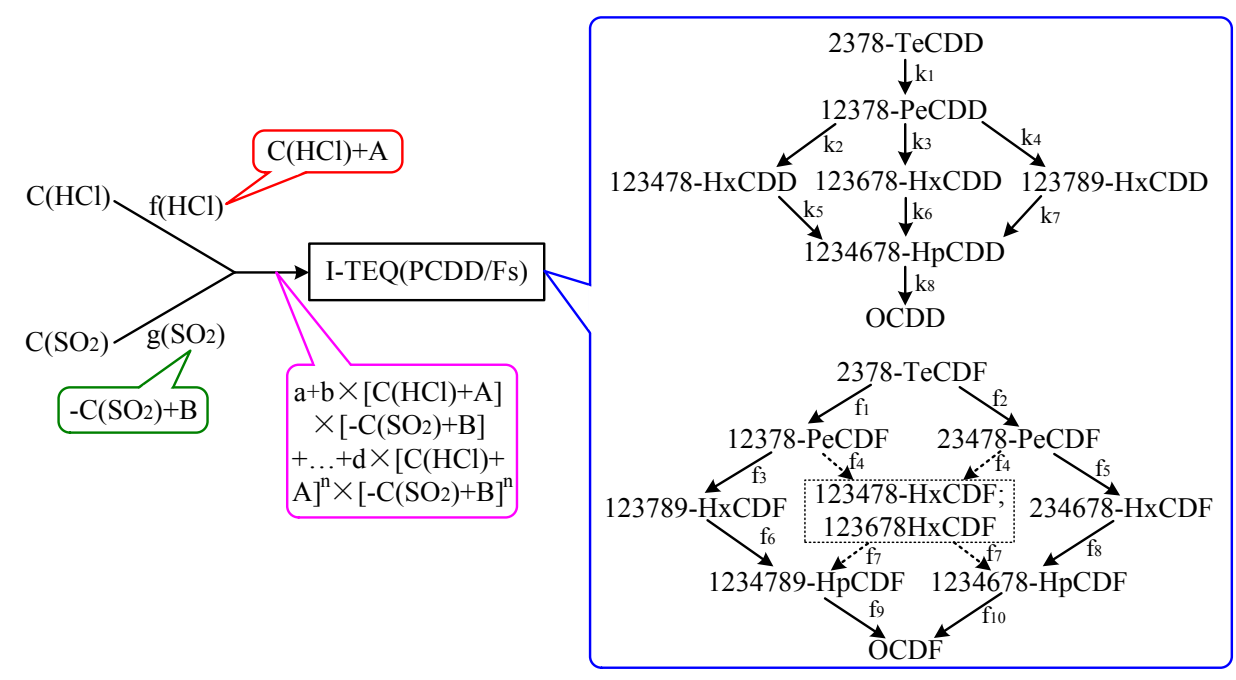

Figure 3. Schematic diagram of the correlation characteristics from PCDD/Fs generation

\subsection{Methodology}

Figure 4 is the logical relationship diagram of the correlation model. Firstly, the experimental data were plotted on a contour line, and the initial output values A and B were performed, while the data points with large deviations were 
eliminated. Then, it would be done to select the associated function expression (initially, $n=1$ ), and randomly select the correlation coefficient, calculate the similarity value $\left(\mathrm{S}_{\text {total }}\right)$, which was used for comparing the size determination with the existing value. If it is less than the original value, the number of calculations is directly determined. While the value is greater than the original value, the coefficients would be replaced, and then the number of calculations is determined. In the judgment of calculating number $(i)$, if $i$ is not more than 10000, the correlation coefficient will be randomly selected again for a new round of optimization. While if $i$ is greater than 10000, the correlation coefficients will be output and the function expression will be determined. When the index ( $n)$ value is less than or equal to $3, i$ will be set to zero again, and a new round of calculation will be carried out. When $n$ is greater than 3 , the calculation would be terminated.

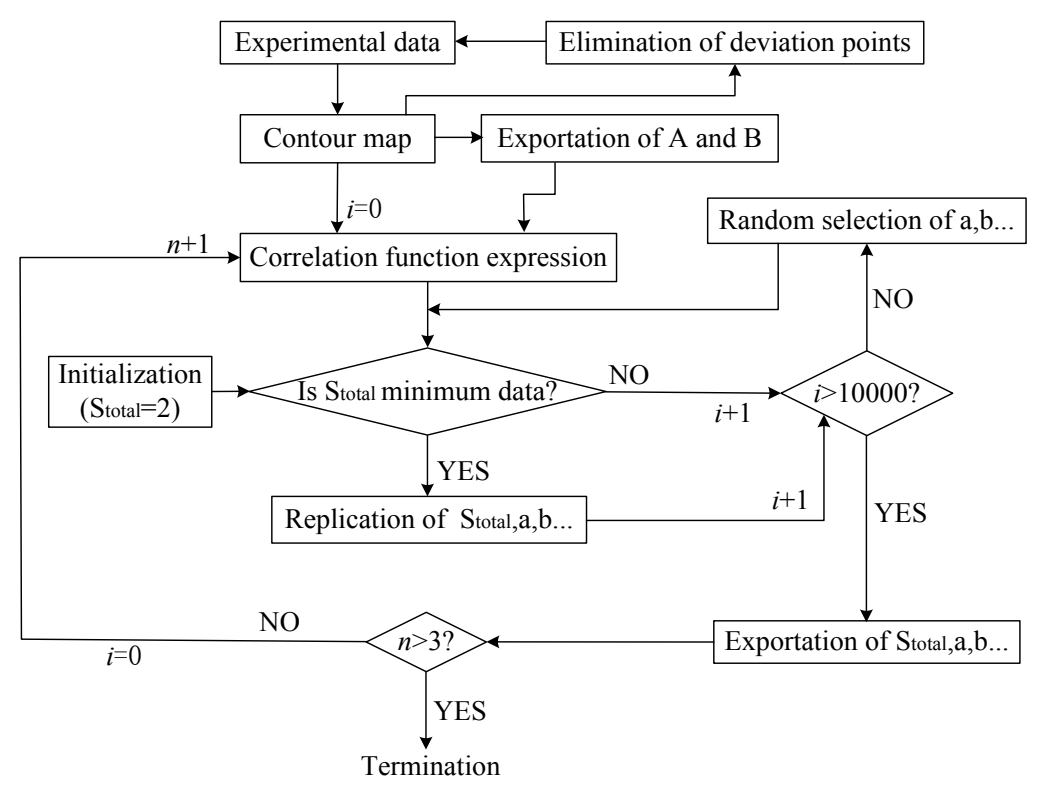

Figure 4. Logical relationship of the correlation model

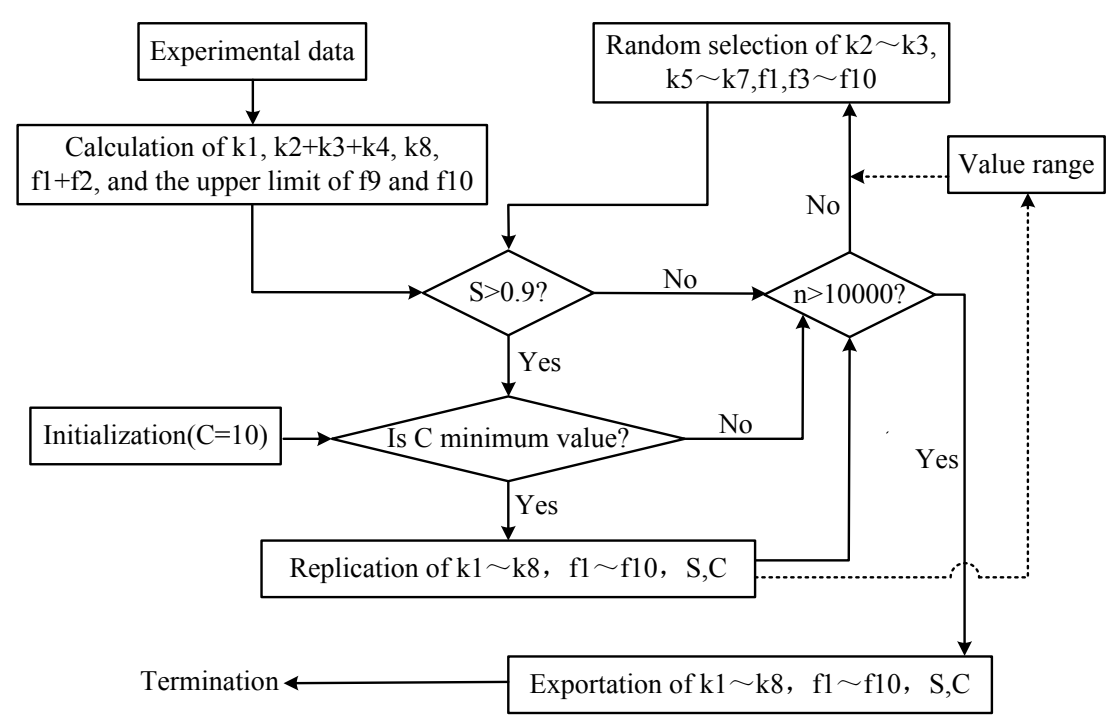

Figure 5. Logical relationship of the pathway-diagnosis method 
Figure 5 shows the logical relationship of the pathway-diagnosis method. It mainly analyzes the probability of the formation of isomers according to the experimental values. The $\mathrm{k} 1 \sim \mathrm{k} 8$ value represents the probability of chlorine substitution among 7 toxic PCDD isomers, and the f1 f10 value represents the probability of chlorine substitution between PCDF isomers. The chlorine substitution combinations were optimized by the evaluation indexes ( $\mathrm{S}$ and $\mathrm{C}$ ) listed in section 2.3. The random method used is based on the theory of most probable probability. Using the most probable method can predict the actual isomer conversion situations to the best possible extent. By combining multiple measurements of experimental data and multiple optimizations of this method, the error is further avoided. A more detailed theoretical overview is available in the reference ${ }^{25}$.

\subsection{Evaluation indicators}

The reliability and accuracy of the prediction model are verified by similarity (S), average percentage content error (C) and average toxicity equivalent (M). ${ }^{25} \mathrm{~S}$ and $\mathrm{C}$ can be used to optimize the compositional accuracy of isomers, while $\mathrm{M}$ was used to evaluate the changing degree of toxicity during the migration of chlorine element. Thereinto, $\mathrm{S}$ represents the difference between the evaluation value and the experimental value. The closer the similarity $\mathrm{S}$ is to 1 , the more accurate the predictions will be. The circumscription of similarity is shown in equation (1).

$$
S=\frac{\sum A_{i} B_{i}}{\sqrt{\sum\left(A_{i}\right)^{2} \sum\left(B_{i}\right)^{2}}}
$$

Among them, the predicted value and experimental value of each component in the PCDD/Fs isomer are represented by $A_{i}$ and $B_{i}$ respectively.

$\mathrm{C}$ is used to further evaluate the accuracy of the predicted value from the perspective of PCDD/Fs isomer percentage content. $C$ is defined as shown in equation (2).

$$
C=\frac{1}{i} \sum\left|A_{i}-B_{i}\right|
$$

Where i represents the PCDDs isomers and PCDFs isomers, respectively.

$\mathrm{M}$ is used for analyzing the toxicity equivalent migration laws of PCDD/Fs isomers, and stands for the accumulation of the percentage content of PCDD/Fs isomers and the corresponding toxicity equivalent product. ${ }^{25}$ Its definition is shown in equation (3).

$$
M=A_{i} \cdot(\mathrm{I}-\mathrm{TEF})_{i}
$$

\section{Results and discussion \\ 4.1 Correlation with $\mathrm{HCl}$ and $\mathrm{SO}_{2}$}

Figure 6 shows the correlation among PCDD/Fs toxic equivalent, $\mathrm{HCl}$ concentration and $\mathrm{SO}_{2}$ concentration. First of all, it can be found that at a specific toxic equivalent, $\mathrm{HCl}$ concentration and $\mathrm{SO}_{2}$ concentration present a hyperbolic trend, which is related to the model set. At the same time, the trend of this correlation curve shows a monotonic trend, and their derivative has a specific inflection point. It can be seen that as the toxic equivalent increases, this inflection point will extend in the direction of lower $\mathrm{SO}_{2}$ concentration and higher $\mathrm{HCl}$ concentration. In addition, it can be determined that at a given concentration of $\mathrm{HCl}$ and $\mathrm{SO}_{2}$, the increase in toxic equivalent caused by changing their concentration values can be regarded as a change in a multi-nomial fitting function, while the specific function relationship is not fixed and it is related to the amount of change. As shown in Figure 7, by comparing the predicted results with the experimental results, it is found that, except for mixing $2 \%$ sludge, the other working conditions are in good agreement. This is because the mixing $2 \%$ sludge is deleted as individual deviation points during the modeling 
process. Thus, in the process of model construction, logarithmic points need to be optimized to further optimize the accuracy of the model. For example, $2 \%$ mixing conditions are eliminated in this work.

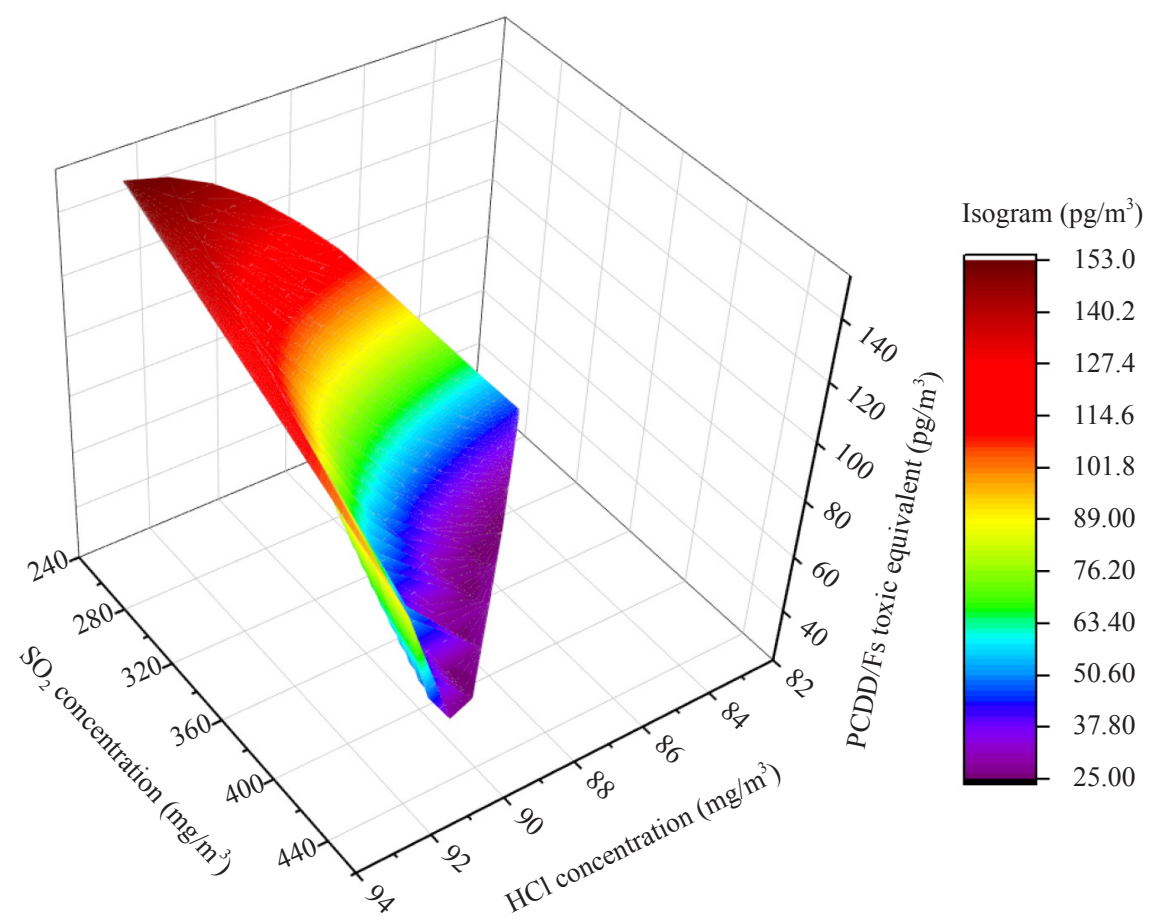

Figure 6. Correlation among $\mathrm{PCDD} / \mathrm{Fs}$ toxic equivalent, $\mathrm{HCl}$ concentration and $\mathrm{SO}_{2}$ concentration

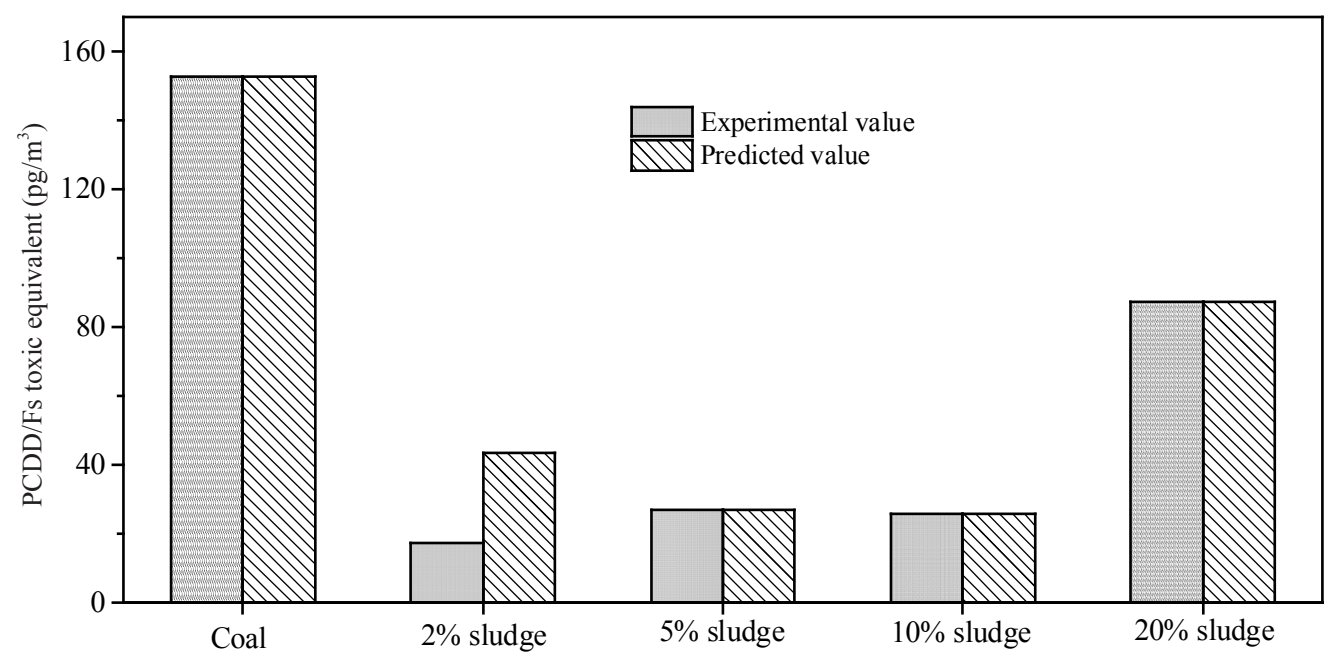

Figure 7. Logical relationship of the pathway-diagnosis method

\subsection{Chlorine substitution probability}

Based on the above analysis, the combustion conditions of mixed $10 \%$ sludge and single pulverized coal were 
selected as the comparison conditions. To further ascertain the effect of mixing sludge on PCDD/Fs generation in coal combustion, the chlorine substitution probabilities of PCDD/Fs isomers were calculated, and these results are shown in Figure 8. It can be found that there are error ranges in these calculated chlorine substitution probability values, which should be related to the accuracy of the chlorine substitution probability value and the error evolution in the calculation process. For PCDDs isomers, mixing sludge significantly increased the chlorine substitution probability in the transformation process of $123678-\mathrm{HxCDD}$ to $1234678-\mathrm{HpCDD}$ and the transformation process of $1234678-\mathrm{HpCDD}$ to OCDD. For PCDFs isomers, mixing sludge significantly increased the chlorine substitution probability in the transformation process of $123789-\mathrm{HxCDF}$ to $1234789-\mathrm{HpCDF}$ and the transformation processes of $1234789-\mathrm{HpCDF}$ and $1234678-\mathrm{HpCDF}$ to OCDF. In conclusion, sludge blending can change the distribution characteristics of PCDD/Fs isomers by changing the specific conversion pathways between the isomers.

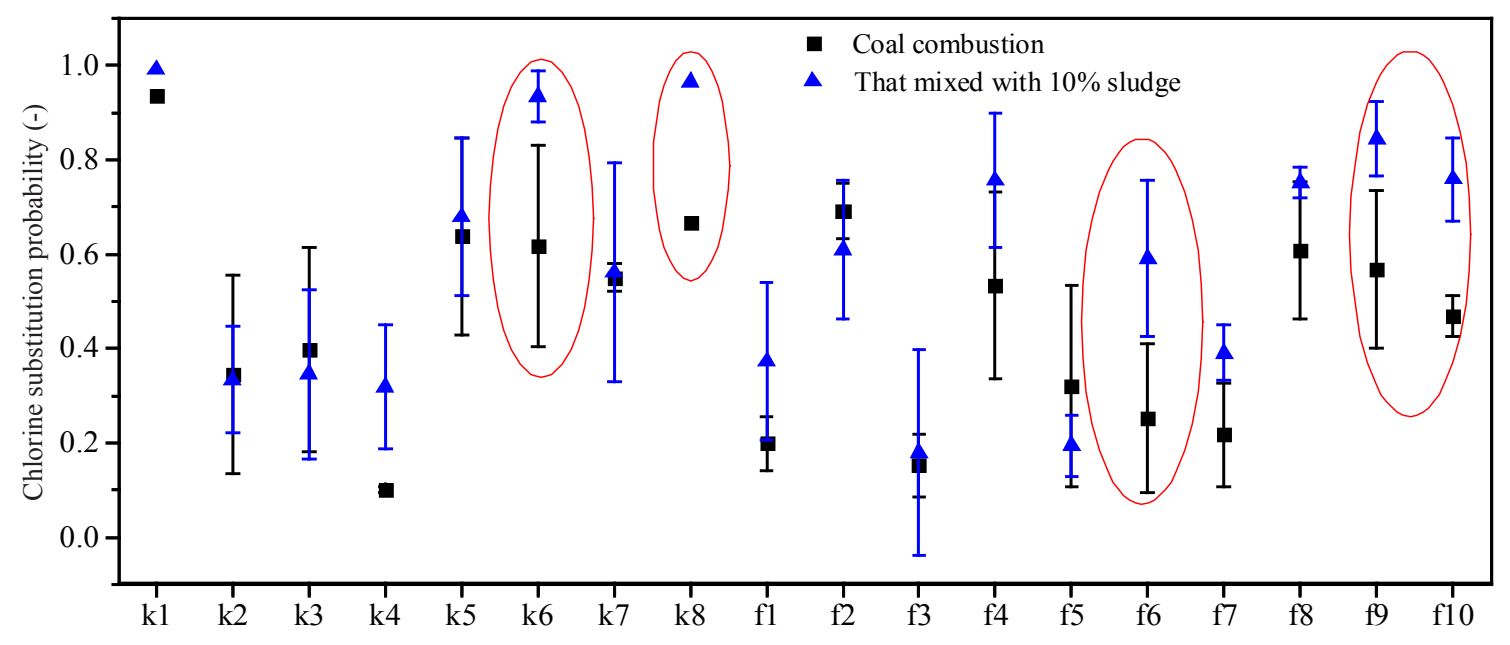

Figure 8. Chlorine substitution probability of PCDD/Fs isomers

\subsection{Chlorine element migration situation}

In order to further explore the influences from mixing sludge on the chlorine migration situation, the migration diagram of PCDD/Fs isomer percentage content (Figure 9) and the average toxic equivalent migration diagram (Figure 10) were drawn respectively. It should be pointed out that the process of increasing the number of chlorine substitutions can also predict the successive advance process brought about by the occurrence of chlorine substitution. For the PCDDs isomers, it can be found from Figure 9(a) that the impacts from mixing sludge are mainly the conversion ratio from 12378-PeCDD to 123478 Hexachlorodibenzo-p-dioxin (123478-HxCDD) and the conversion ratio from 1234678-HpCDD to OCDD. While it can be found from Figure 10(a) that the main reason that the mixing sludge reduces the average toxic equivalent of PCDDs is the increased chlorine substitution probability of 12378-PeCDD at position 4. Similarly, it can be found from Figure 9(b) that the mixing sludge caused many changes in the PCDFs isomers content, mainly including the further chlorine substitution probability of $2378-\mathrm{TeCDF}$, as well as the generation situation of 1234(6)78 Hexachlorodibenzo-p-furan [1234(6)78-HxCDF], 1234789-HpCDF, and OCDF. However, it can be found from Figure 10(b) that the main reasons for mixing sludge to further reduce the average toxic equivalent of PCDFs isomers in coal combustion are the decrease in the chlorine substitution probability of 2378-TeCDF at position 4 , as well as the increase in total probability of further chlorine substitution for 23478-PeCDF, 123478-HxCDF and 123678-HxCDF. 

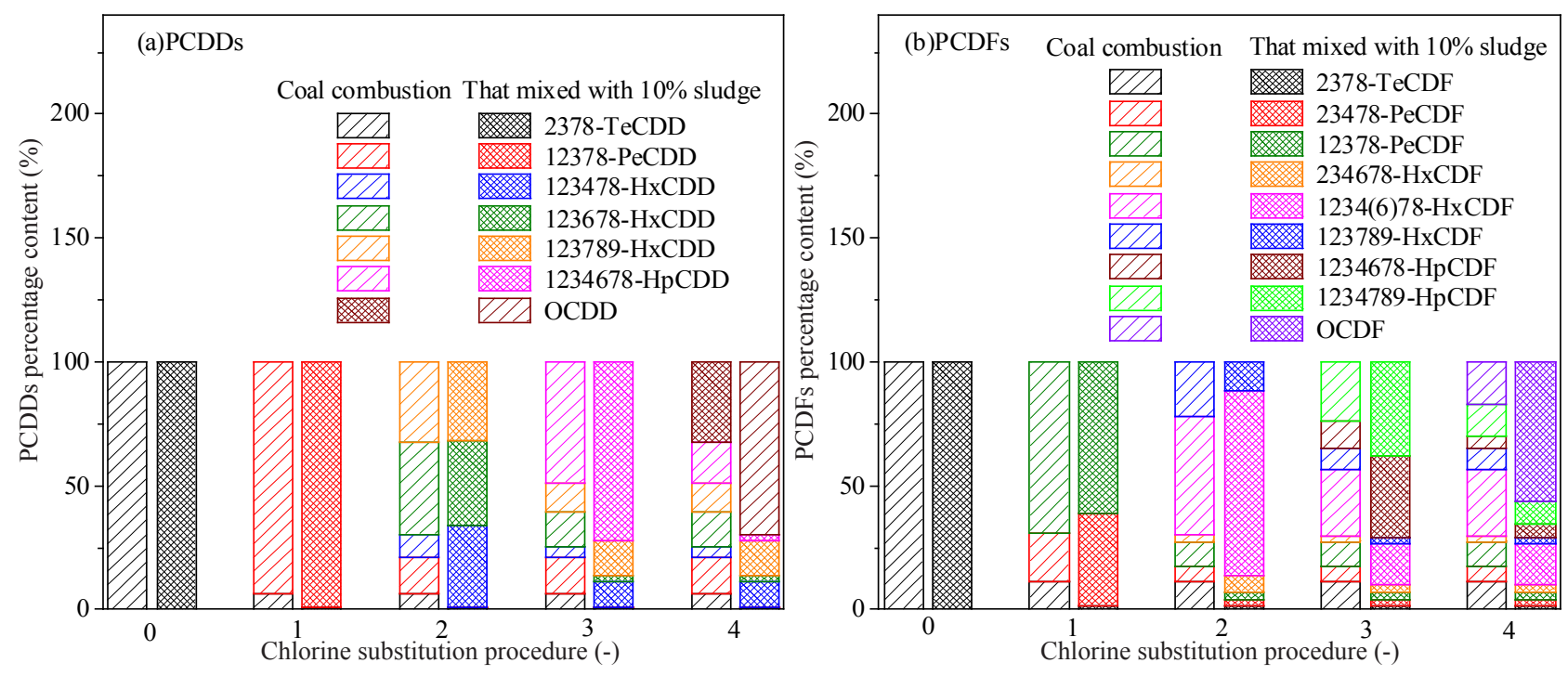

Figure 9. Percentage content of PCDDs(a) and PCDFs(b)
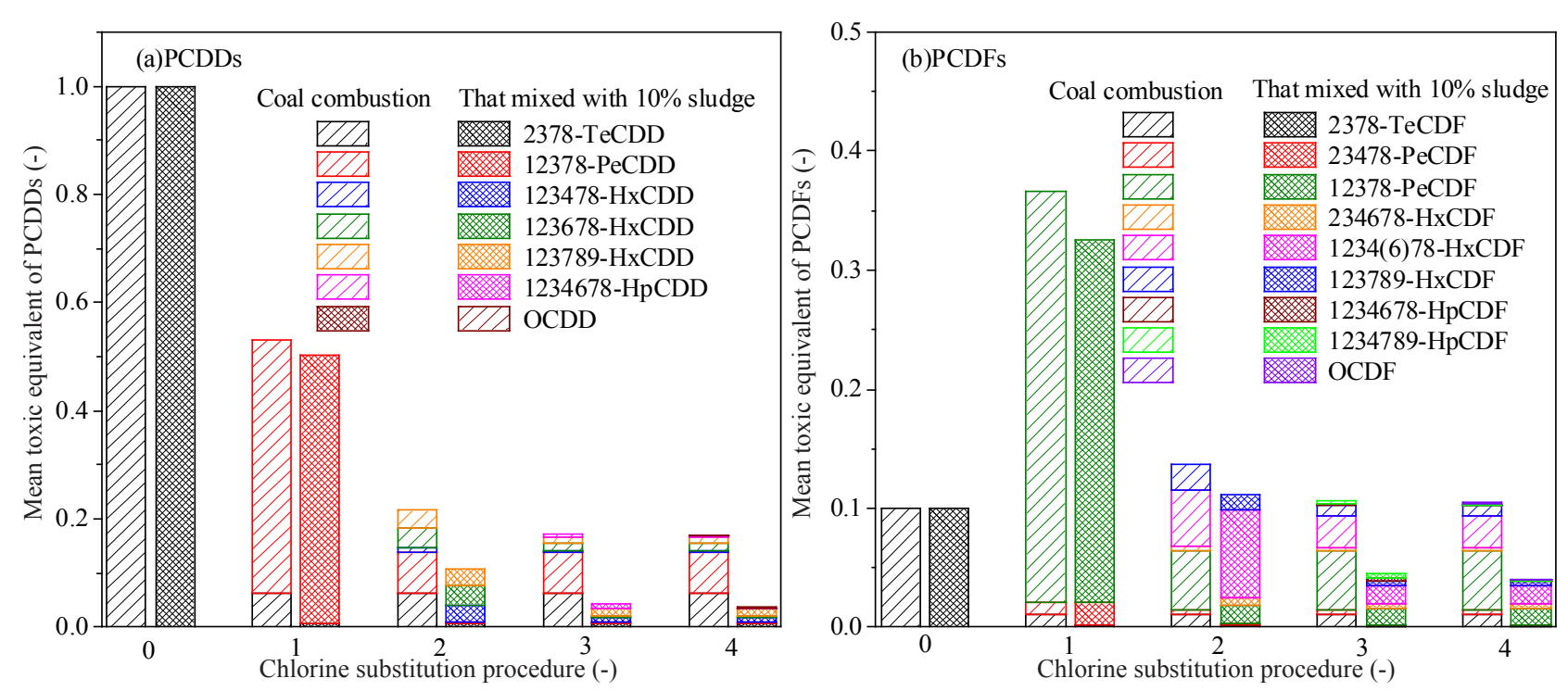

Figure 10. Average toxic equivalent of PCDDs(a) and PCDFs(b)

\subsection{Function pathway of mixing sludge}

To elaborate the functional pathways of sludge mixing on the formation of PCDD/Fs isomers from coal combustion, the main functional pathways and key toxic pathways emerge respectively according to the above results, as shown in Figure 11. Obviously, Figure 11 not only clarifies the effect of sludge mixing on the transformation among $\mathrm{PCDD} / \mathrm{Fs}$ isomers, but also points out the main reasons for changing the toxic equivalent distributions of PCDD/Fs isomers, which provides a new idea for the follow-up related technology research. What's more, the application of functional pathways diagnosis can distinguish the transformation among PCDD/Fs isomers for the number of substances from the transformations among PCDD/Fs isomers for the toxic equivalent, which is conducive to exploring the inhibition or promotion pathways from the perspective of microscopic mechanism, and is also conducive to the artificial 
intervention of specific PCDD/Fs toxic isomers. At the same time, it provides a theoretical basis for adjusting the ratio of solid waste to inhibit the formation of PCDD/Fs.

(a)

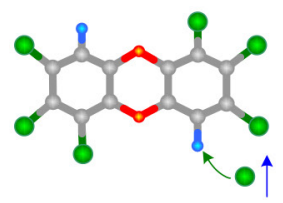

(e)

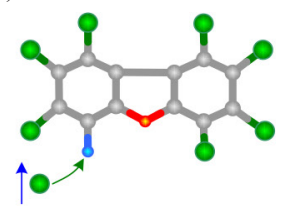

(i)

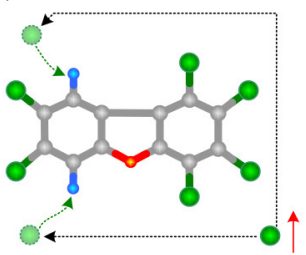

(b)

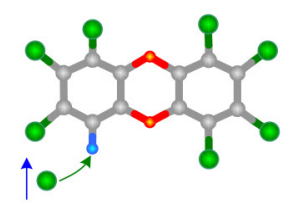

(f)

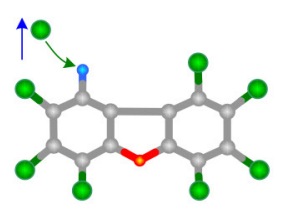

(j)

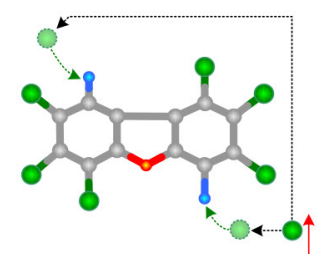

(c)

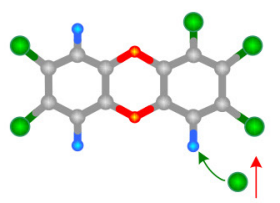

(g)

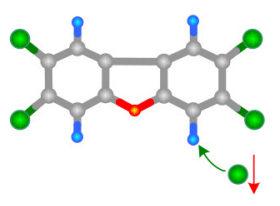

(d)

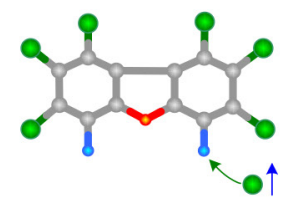

(h)

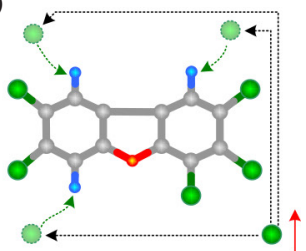

Figure 11. Functional pathways of mixing 10\% sludge for PCDD/Fs isomers

\section{Conclusion}

In view of the effect of sludge mixing on the distribution characteristics of PCDD/Fs isomers in the coal combustion process, a correlation model of PCDD/Fs toxic equivalent was proposed to quantitatively analyze the correlation between $\mathrm{HCl}$ and $\mathrm{SO}_{2}$ concentrations, and meanwhile a method for diagnosing the transformation pathways among PCDD/Fs isomers was used to deeply analyze the PCDD/Fs distribution characteristics of coal combustion and that mixed with $10 \%$ sludge, respectively. The specific conclusions are as follows:

(1) There is the trend of this correlation curve with a monotonic trend form at a specific toxic equivalent, and meanwhile their derivative has a specific inflection point. This inflection point will extend in the direction of lower $\mathrm{SO}_{2}$ concentration and higher $\mathrm{HCl}$ concentration with the toxic equivalent increases.

(2) The sludge mixing mainly improved five transformation pathways, including the conversion process from 123678-HxCDD to 1234678 -HpCDD, the conversion process from 1234678 -HpCDD to OCDD, the conversion process from $123789-\mathrm{HxCDF}$ to $1234789-\mathrm{HpCDF}$, and the conversion process from 1234789-HpCDF and 1234678-HpCDF to OCDF.

(3) Increasing the chlorine substitution probability of 12378-PeCDD at position 4, decreasing the chlorine substitution probability of 2378-TeCDF at position 4, and increasing the total probability of further chlorine substitution for 23478-PeCDF, $123478 \mathrm{HxCDF}$ and 123678-HxCDF, respectively, are the main reasons for further reducing the average toxic equivalent of $\mathrm{PCDD} / \mathrm{Fs}$ isomers produced in coal combustion with sludge mixing. 


\section{Conflict of interest statement}

The authors declare no competing financial interest.

\section{Acknowledgments}

These authors were supported by the "Natural Science Foundation of Hebei Province (E2020502007)" and "Central University Fund Project (2020MS103)".

\section{References}

[1] Pham, M. T. N.; Anh, H. Q.; Nghiem, X. T.; Tu, B. M.; Dao, T. N.; Nguyen, M. H. Chemosphere. 2019, 225, 238246.

[2] Ren, M.; Lv, Z.; Xu, L.; Lu, Q.; Zhang, X.; Yu, Y.; Fan, Y.; Gao, Y.; Chen, J.; Zhang, H. Sci. Total Environ. 2020, $735,1-8$.

[3] Maric, J.; Vilches, T. B.; Pissot, S.; Vela, I. C.; Gyllenhammar, M.; Seemann, M. J. Waste Manag. 2020, 102, $114-$ 121.

[4] Ma, H.; Du, N.; Lin, X. Sci. Total Environ. 2018, 633, 1263-1271.

[5] Nida, G.; Bushra, K.; Hizbullah, K.; Said, M.; Iqbal, A.; Nayab, G. Arab. J. Geosci. 2021, 14(9), 1-10.

[6] Wei, J. X.; Li, H.; Liu, J. G. Chemosphere. 2021, 276(9-11), 130166.

[7] Chen, Z.; Lin, X.; Lu, S.; Li, X.; Yan, J. Chem. Eng. J. 2019, 359, 1391-1399.

[8] Chen, Z.; Lin, X.; Lu, S.; Li, X.; Qiu, Q.; Wu, A.; Ding, J.; Yan, J. Chemosphere. 2018, 208, 862-870.

[9] Yang, M. H.; Chen, Y.; Liu, J. H.; Li, J. Y.; Lu, J.; Zhang, R. Z. Indust Heat. 2020, 49(5), 44-47.

[10] Lin, S. L.; Lee, K. L.; Wu, J. L.; Cheruiyot, N. K. J. Waste Manag. 2019, 95, 316-324.

[11] Wang, Y.; Qian, L.; Yu, Z.; Chun, T.; Long, H.; Wu, X. Aerosol Air Qual Res. 2020, 20, 2568-2579.

[12] Hsu, Y.; Chang, S.; Chang, M. B. Chemosphere. 2021, 280, 130645.

[13] Chen, Z.; Lin, X.; Zhang, S. J. Hazard. Mater. 2021, 416, 126216.

[14] Han, Z. X.; Li, J.; Gu, T. B.; Yang, R. L.; Fu, Z. F.; Yan, B. B.; Chen, G. Y. J Anal Appl Pyrolysis. 2021, 157, 105240.

[15] Zhong, R.; Wang, C.; Zhang, Z.; Liu, Q.; Cai, Z. J. Waste Manag. 2020, 106, 110-119.

[16] Cai, P.; Zhan, M.; Ma, H.; Xu, X.; Chen, T.; Li, X. D. Energy Fuels. 2020, 34, 2346-2354.

[17] Fujimori, T.; Toda, A.; Mukai, K.; Takaoka, M. J. Hazard. Mater. 2020, 382, 1-7.

[18] Gao, Q.; Edo, M.; Larsson, S. H.; Collina, E.; Rudolfsson, M.; Gallina, M.; Oluwoye, I.; Altarawneh, M.; Dlugogorski, B. Z.; Jansson, S. J Anal Appl Pyrolysis. 2017, 123, 126-133.

[19] Wang, J. X. Study on chemical looping combustion of plastic wastes for controlling the emission of PCDD/Fs[D]; Doctoral dissertation of Huazhong University of Science and Technology, 2016.

[20] Gan, M.; Wong, G. J.; Fan, X. H.; Ji, Z. Y.; Ye, H. D.; Zhou, Z. A.; Wang, Z. C. J. Clean. Prod. 2020, 291(3), 125286.

[21] Zhao, H.; Wang, J. Combust Flame. 2018, 191, 9-18.

[22] Chen, Z. L.; Lin, X. Q.; Zhang, S.; Zou, X. B.; Li, X. D.; Lu, S. Y.; Yan, J. H. J. Hazard. Mater. 2021, $416,126216$.

[23] Zhang, S.; Jiang, X.; Lv, G.; Wu, L.; Li, W.; Wang, Y.; Fang, C.; Jin, Y.; Yan, J. Fuel Process. Technol. 2019, 184, 57-64.

[24] Ying, Y.; Ma, Y.; Li, X.; Lin, X. Chemosphere. 2021, 265, 129120.

[25] Wang, J. X.; Song, H. W.; Zhang, Y. L. Energ Fuel. 2021, 35, 1741-1749. 